\title{
A computação na sociedade palestina: Um estudo de caso
}

\section{Computing in Palestinian society: A case study}

\author{
Cristiane Aquino, Marcelo Teixeira, Diogo Homenick, André Santos, Alexandre Gomes, Jhonatas Silva \\ Universidade Federal Rural de Pernambuco
}

\begin{abstract}
Resumo
Como proposta para o presente estudo, destacamos um estudo de caso comparativo de utilização de recursos tecnológicos no sistema educacional Autoridade Nacional Palestina. O trabalho qualitativo e empírico descritivo foi desenvolvido no Departamento de Estatística e Informática da Universidade Federal Rural de Pernambuco (Brasil), no período de fevereiro a maio de 2017.

Palavras chave: Palestina, Israel, Tecnologia, Educação, Interatividade.
\end{abstract}

\begin{abstract}
As a proposal for the present study, we highlight a comparative case study of the use of technological resources in the educational system Palestinian National Authority. The qualitative and empirical descriptive work was developed in the Department of Statistics and Informatics of the Federal Rural University of Pernambuco (Brazil), from february to may 2017.

Keywords: Palestine, Israel, Technology, Education, Interactivity.
\end{abstract}

\section{Introdução}

A ascensão da "cultura da informação e da participação" (ubíqua, interativa, colaborativa e digitalizada), durante a era pós-moderna ratificou no "imaginário acadêmico" uma cultura imanente da sociedade em rede ou "cibercultura", apesar das duras críticas ao "modus operandi" desse segmento ideológico, como salienta Zygmunt Bauman (2001), em "Modernidade Líquida". A Sociedade Líquida de Bauman é caracterizada pela instabilidade e pela ambiguidade, a erosão do que pareciam ser categorias estáveis de identidade e a fragmentação da experiência em condições de mudanças tão rápidas que as formas sociais e as instituições não têm mais tempo para solidificar a identidade humana e a ação coletiva (Vint, 2008). Adjacente a crítica de Bauman, observamos o ceticismo sócio-tecnológico de Fredric Jameson (1996) citado em Teixeira (2013) averso às verdades oblíquas do período pós-modernista enquanto propulsor de uma nova ordem sociocultural. No mesmo sentido, Baudrillard (1981) o acompanha em "Simulacres et Simulation", condicionado a questionar à dicotomia mídia/cultura digital, sempre associado às transformações da "sociedade de consumo", caracterizada pela universalidade totalitária dos meios de comunicação de massa enquanto produtores da realidade virtual (utópica e dissimulada).

Ancorada nas análises de Jameson, Vargas (1997) em Aquino e Teixeira (2015) sustenta que na lógica pósmoderna a última transformação do espaço, com o surgimento do hiperespaço, fez com que o ser humano perdesse a capacidade de se localizar corporalmente e de se organizar, através da percepção, o espaço que o circunda e, por extensão, de reconhecer sua posição no mundo físico. É um ponto de separação - entre o corpo humano e o ambiente construído - que pode servir como analogia para a nossa incapacidade mental de mapear a enorme rede gobal e multinacional de comunicação em que nos encontramos presos, afirma a autora visivelmente influenciada pela literatura de Jean Baudrillard.

Afora às críticas, sem idilismo ideológico, concluímos que novos modos de vida são permeados por uma cultura global que potencializa novas formas de sociabilidade no mundo contemporâneo através de tecnologias digitais, princípio "sine qua non" da denominada "cibercultura". Em outras palavras, trata-se de uma virtualização cultural da realidade humana, fruto da migração do espaço físico para o virtual (mediado pelas TICs), regido por códigos, signos e relações sociais próprias. Avante, surgem formas instantâneas de comunicação, interação e possibilidade de rápido acesso às informações, no qual não somos meros emissores, mas produtores, reprodutores, colaboradores e distribuidores daquelas. As novas tecnologias também têm servido para "conectar" pessoas de diferentes culturas fora do espaço virtual, o que há pelo menos cinquenta anos era impensável. Nessa gigantesca teia de relacionamentos, absorvemos, reciprocamente, crenças, costumes, valores, leis, hábitos, uns dos outros, heranças culturais eternizadas por uma dinâmica físico-virtual em permanente metamorfose (Teixeira, 2012), como vemos na sociedade palestina, apesar do cenário de crise humanitária causada pelos conflitos com o Estado de Israel.

\section{Método}

O presente estudo é de cunho qualitativo e de cariz empírico descritivo, dedicado a descrever como a tecnologia na educação é utilizada na sociedade da Autoridade Nacional Palestina, em 2017. Para tanto, o trabalho de pesquisa foi norteado pelos estudos de 
campo do pesquisador da Universidade Federal Rural de Pernambuco Marcelo Mendonça Teixeira, realizada presencialmente em 2014. Enquanto método, trata-se de uma revisão de literatura baseada em estudo de caso. Todas as áreas de pesquisa, independente da sua classificação (seja com base nos seus objetivos, procedimentos técnicos ou fontes de informação), exigem uma pesquisa bibliográfica prévia, ponderam Cruz e Ribeiro (2004). Gressler (2004, p.131) comprova a veracidade da afirmativa, pois "para que a uma investigação seja bem-sucedida, supõe-se que o pesquisador já tenha conhecimento prévio do assunto. $\mathrm{O}$ objetivo da revisão da literatura seria, então, a atualização e integração desse conhecimento. Já no estudo de caso, procuramos apreender o contexto de uma situação e, criativamente, interpretar e descrever a complexidade de um caso concreto, mediante um mergulho profundo e exaustivo em um objeto delimitado, diz Martins (2008). A pesquisa em voga foi realizada no período de fevereiro a maio de 2017.

\section{Resultados}

\section{A Educação Tecnológica na Palestina}

A Autoridade Nacional Palestina é reconhecida como país pela Organização das Nações Unidas e por mais de 130 países, incluindo o Vaticano e o Brasil. Foi criada por meio do Acordo de Oslo (1993-95), firmado entre Israel e a Organização pela Libertação da Palestina (OLP), com mediação dos EUA, a ANP administra nominalmente partes da Cisjordânia e da faixa de Gaza. Sua capital é Ramallah e Jerusalém Ocidental (na Cisjordânia). Jerusalém igualmente é declarada, mas não reconhecida pela comunidade internacional, por Israel, como capital. Com apenas 365 quilômetros quadrados, a capital da Faixa de Gaza é Gaza e faz fronteira com o Egito e Israel. Outras importantes cidades são Khan Yunis, Rafah e Dayr Al-Balah. Mahmoud Abbas, do partido Fatah, é o atual presidente da Autoridade Nacional Palestina (Teixeira, 2014).

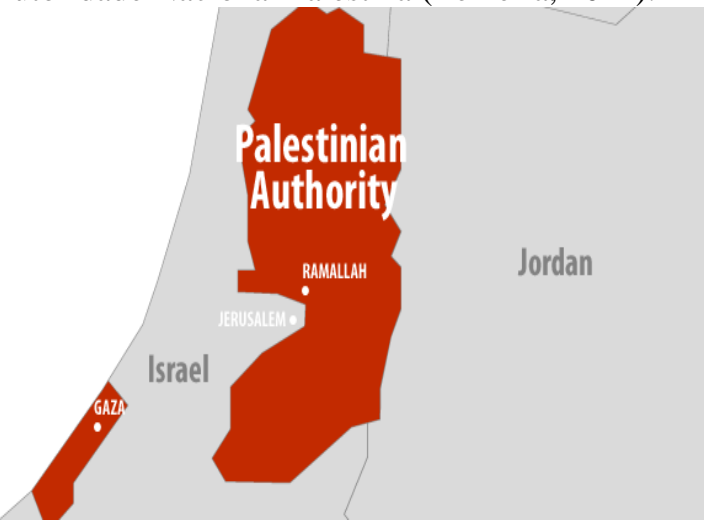

Figura 1. Mapa da Palestina

Fonte:http://www.worldcoalition.org/Palestinian-Authority

A Educação na Palestina limita-se aos territórios da Cisjordânia, parcialmente ocupada militarmente por Israel, mas reclamada pela Autoridade Palestina (controlada pela Fatah - Harakat al-Tahrir al-Watani alFilastini ou Movimento de Libertação Nacional da Palestina) e pela Jordânia, e a Faixa de Gaza (controlada pelo Hamas - Harakat al-Muqāwamat al-Islāmiyyah ou Movimento de Resistência Islâmica). Tanto na Cisjordânia quanto em Gaza, o sistema educacional é administrado pelo Ministério Palestino de Educação e Ensino Superior. São três diferentes tipos de escolas seccionadas a partir de gênero em territórios palestinos, de acordo com Mustafa e Bisharat (2008), a escola de meninos, a escola de meninas e a escola co-educacional divididas em graus, no ensino básico, do $1^{\circ}$ ao $10^{\circ}$. O ensino secundário representa $\mathrm{o}$ ensino médio ou profissionalizante (em escolas técnicas), abrangendo o $11^{\circ}$ e $12^{\circ}$ graus e, por fim, o ensino superior, com cursos de graduação em diferentes campos do saber, oferecidos em 13 instituições de ensino (públicas e privadas), algumas das quais oferecem cursos de pós-graduação, além de institutos de pesquisa em Jerusalém e em Gaza. Em relação ao currículo, a Educação segue a manuais, padrões e regulamentos próprios, em parte, influenciados pela "UNESCO International Institute For Educational Planning" e pelo sistema árabe de ensino. Também existe as Escolas-Albergue da Agência da ONU para Refugiados Palestinos, na Faixa de Gaza.

A estrutura administrativa da Educação é composta de diretorias (escritórios distritos), divididos na Cisjordânia e na Faixa de Gaza. A Al-Quds Open University é especializada em ensino à distância para a comunidade palestina e a Universidade de Al-Aqsa, em Gaza, se destaca por exportar "mentes" para as melhores universidades de tecnologia norte-americanas. $\mathrm{O}$ financiamento para a Educação se origina do orçamento do governo através do Ministério das Finanças Palestino conjuntamente com doações de organismos internacionais, como a UNESCO. As escolas da ONU e as faculdades comunitárias recebem verba da União Europeia. Nos últimos anos, a Universidade Islâmica de Gaza vem se destacando como uma das principais instituições de ensino superior do Oriente Médio, aliás, competindo, em algumas áreas, com instituições consagradas mundialmente, como a Universidade Hebraica de Jerusalém, a Universidade de Haifa e a Universidade de Tel Aviv (em Israel), a Universidade King Saud e a King Abdulaziz (na Arábia Saudita). Recentemente, estabeleceu um acordo de cooperação com a Universidade do Porto, de Portugal, para o intercâmbio de pesquisadores e estudantes, e a realização de eventos acadêmicos entre ambas instituições (seminários, workshops, palestras). Tal universidade tem parceria com mais de 143 institutos acadêmicos e organizações em todo o mundo (ibidem).

O livro de Nasser, Berlin e Wong (2011) "Examing education, media and dialog under occupation: the case of Palestine and Israel", desmistifica como palestinos, não somente universitários, entendem e se comunicam bem em Inglês, num cenário de educação precária. Os Acordos de Oslo, em 1993, propiciaram o surgimento da Autoridade Nacional Palestina, compreendendo as Regiões da Cisjordânia e da Faixa de Gaza, e frente a um panorama de reconhecimento internacional como "Estado" no futuro, era necessário investir na segunda língua, além do Árabe. Daí, houve uma mudança no currículo e todas as instituições de ensino introduziram tal idioma na grade curricular do ensino básico ao 
superior. Inclusive, por receberem alunos estrangeiros de intercâmbio e professores pesquisadores de várias nacionalidades, é muito comum o diálogo em Inglês nos campus acadêmicos, como podemos verificar na Universidade de Birzeit (Cisjordânia), e na Universidade Islâmica de Gaza.

Em contrapartida, as restrições de acesso ao mercado de trabalho em Israel e a escassez deste nos territórios palestinos influenciam negativamente na perspectiva dos jovens em fazer um curso superior, tanto na Faixa de Gaza quanto na Cisjordânia. Ainda, as limitações orçamentárias para a aquisição de materiais didáticos, computadores e softwares, entre outros problemas inerentes a um cenário de conflito entre dois países há décadas, reduzem, consequentemente, as possibilidades de crescimento e a oferta de ensino na Palestina.

Por conta dos conflitos com Israel, existe preconceito no universo acadêmico Ocidental sobre o desenvolvimento tecnológico na Palestina e o "achismo", sem conhecimento de causa, prejudica, efetivamente, a imagem do país em busca de reconhecimento científico da comunidade internacional. A realidade é inversa quando presenciamos os fatos "in loco". Em 2013, a pertinente reportagem do Jornalista Guilherme Pavarin da Revista Galileu "Conexão Palestina" citado nos estudos de Teixeira (2014), reforça nossos argumentos. Oportuno para o presente artigo, citamos partes do texto de Pavarin: "Nos últimos meses, a atuação dos militantes digitais da Palestina tem se voltado a trazer as universidades para próximo do setor da tecnologia"..."Entre as startups que concorrem aos investimentos estão ideias promissoras. Uma delas, chamada "imbox" é um aplicativo que cria listas inteligentes de músicas com base em grupos de amigos. O autor, Mohammad Khatib, um engenheiro de software de 24 anos, cabelos compridos e de passagem pelo Google, explica que o programa pode detalhar com precisão se os usuários gostarão de uma música escaneando tudo o que falam e dizem pela internet. "Estamos usando essa plataforma para entender como as interações das pessoas influenciam as outras", diz. "Depois poderemos aplicar às áreas de notícias, artigos, e assim por diante".

Jerusalém é, sem dúvida, uma das cidades mais impressionantes em relação à "tolerância" do mundo, ao agregar os bairros armênio, cristão, judeu e mulçumano, cada qual com seus ritos e atribuições específicas em locais sagrados. Idem foi à tolerância nas escolas e universidades para realização da presente pesquisa, mas limitada, em algumas ocasiões, pela segurança escolar, que não permitia fotografias ou filmagens sem prévia autorização. Enquanto o povo palestino é prejudicado pelos grupos radicais islâmicos, sem possibilidade de diálogo coerente, pois as exigências que demandam nenhuma nação conseguiria atender, Israel têm ilhas acadêmicas de excelência, como a Universidade Hebraica de Jerusalém, o Instituto de Tecnologia de Israel e o Instituto Weizmann de Ciência, entre as 100 melhores universidades do mundo em 2014, segundo a "Academic Ranking of World Universities", de onde nascem prêmios nobel e reconhecimento internacional. Em visita a Universidade de Tel Aviv, por exemplo, em
Julho de 2014, foi-nos facultado um mapa virtual do campus universitário para chegar a Escola de Educação, quanto normalmente seria deslocado um funcionário para guia-nos até o local de encontro.

Em 2017, constatamos que não houve mudanças significativas nos territórios palestinos quanto à utilização de tecnologias no processo de ensino e aprendizagem, pois a restrição aos recursos tecnológicos por parte de Israel vem sendo cada vez mais intensificadas (por motivos diversos). Barreiras físicas (muros) limitam a entrada de computadores, tablets, smartphones, além do material didático para as instituições de ensino (bloqueio marítimo do estreito de Tiran (a via em direção ao golfo de Áqaba e ao porto israelense de Eilat, é outro exemplo). Deste modo, a realidade presenciada pelo pesquisado Marcelo Teixeira permaneceu inalterada: "Desde 1990 que os livros e artigos de Riad Malki denunciam que os israelenses impõem normas restritas ao desenvolvimento científico e tecnológico das universidades palestinas, entre as quais se prolongam até 2014, como: a não expansão do ensino universitário e construção de novas instalações (departamentos e centros de ensino), dificuldades para a entrada de equipamentos de laboratórios na Faixa de Gaza, computadores e livros para as bibliotecas apreendidos, etc., escreve Malki (2012). Nesta seara de absurdos, autorizações de viagem negadas a professores universitários para a participação de eventos acadêmicos no exterior. Ainda, uma ordem militar que impede a circulação, venda e manutenção como bens de uso pessoal, de nada menos que 6 mil títulos de obras, livros didáticos e publicações científicas, conta o estudioso Riad (ibidem). Os fatos exprimem um receio infundado no crescimento científico das universidades palestinas como elevadores panorâmicos para o discurso ultranacionalista dos grupos Hamas e Jihad Islâmica e/ou o desenvolvimento/aprimoramento de armas e técnicas de guerrilha contra a população judia. É claro que há lógica no medo por trás dessa ideologia repressora, afinal, o "Bloco de Estudantes Islâmicos" é um movimento precursor do Hamas e nasceu na Universidade Islâmica de Gaza” (Teixeira, 2014).

Igualmente, destacam-se as operações militares de Israel contra os territórios da faixa de Gaza. Uma das quais foi a "Operation Cast Lead", onde Israel destruiu duas escolas palestinas mantidas pela ONU, sendo um centro de formação e uma escola para meninas, e bombardeou o Departamento de Ciências da Universidade de Gaza. Por outro lado, Israel alega que se previne contra o risco eminente de ataques terroristas vindo de cidadãos palestinos (uma realidade), especialmente em áreas de assentamento para a construção de novas habitações para judeus (supostamente, ilegais, afirmam os palestinos e árabesisraelenses). 


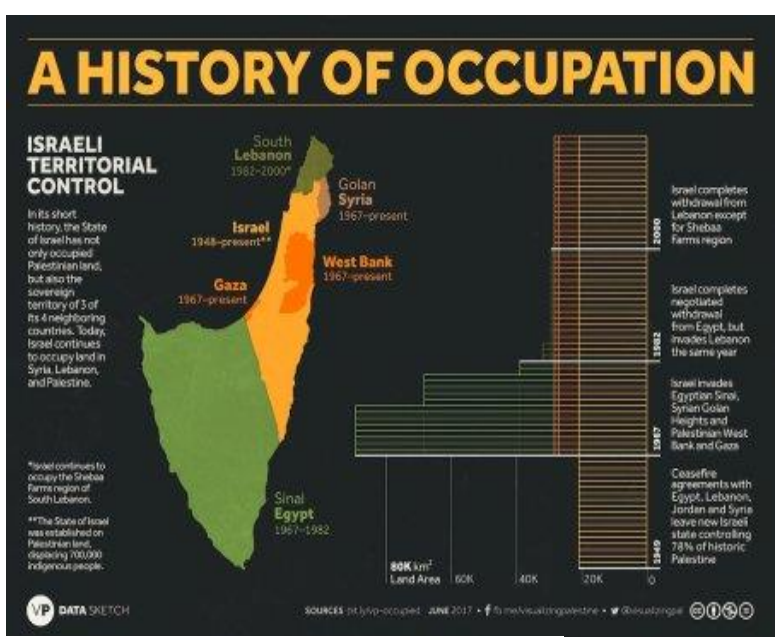

Figura 2. Mapa de Ocuação na Palestina

Fonte: https://psnedmonton.ca/

O que vemos é uma ocupação gradativa e permanente de Israel com a expansão dos assentamentos judaicos, juntamente com as práticas de limitação explicitadas em epígrafe. Contudo, não superou a

\section{Al Nayzak - Tecnologia Palestina na Educação: O Estudo de Caso}

Al Nayzak é uma iniciativa sem fins lucrativos desde 2007, não partidária, de Jerusalém e única que procura jovens talentos em ciência, tecnologia, engenharia e matemática e planta uma visão ambiciosa nos corações da nossa comunidade: "Desenvolver e reforça uma nova cultura que abraça a ciência e anuncie essa cultura entre a juventude palestina, de modo que sua competência em ciências aplicadas produtivas possa proporcionar-lhes melhores oportunidades econômicas que levariam à sua prosperidade futura". Na prática, Al Nayzak é uma organização palestina sem fins lucrativos de Jerusalém, especializada em educação, extensão e pesquisa. A abordagem de Al Nayzak é fazer com que as habilidades de pensamento científico se tornem uma parte inerente da vida do povo palestino. Para fazer isso, aplica recursos tecnológicos para ajudar os indivíduos a adquirirem habilidades de pensamento e relacioná-las com um verdadeiro saber-fazer e tecnologia. Eles se tornam capazes de enfrentar desafios em sua jornada para alcançar a excelência e ajudar a desenvolver o e construir uma sociedade palestina moderna (www.alnayzak.org/page.php?id=216fy8559Y216f).

Para alcançar sua missão, a organização adotou uma série de programas crônicos que visam várias faixas etárias para incubar pessoas talentosas desde uma idade precoce, incluindo Incubadoras de estudantes talentosos para crianças e adolescentes de 10 a 14; Jovens pesquisadores para as pessoas de 14 a 17 anos; Empreendedorismo Científico e Tecnológico (STEP) para estudantes de 14 a 17 anos; "Made in Palestine" para quem tem 18 anos ou mais; E " Tafkeer", programa de tecnologia de pensamento que integra tecnologia na educação nas escolas. Há também uma série de projetos complementares para transmitir uma mensagem de ciência e conhecimento a todos os segmentos da sociedade (ibidem). Al Nayzak atende todas as áreas palestinas através de sua rede de escritórios em Jerusalém, Ramallah, Gaza e Nablus, bem como na Casa de Ciência e Tecnologia da Cidade Velha de Birzeit. Abaixo, destacamos o site interativo da Al Nayzak e o seu ambiente de games, nas figuras 3 e 4:

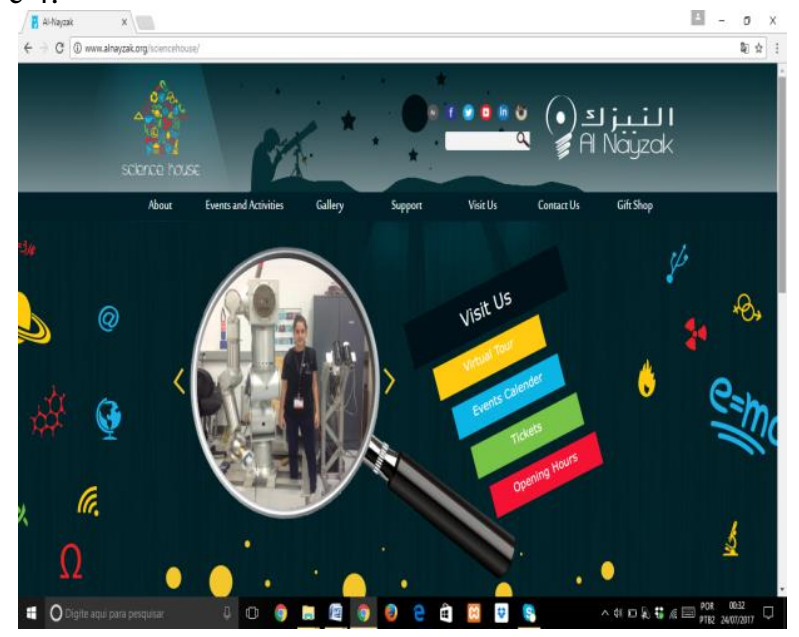

Figura 3. Website da Al Nayzak

Fonte: http://www.alnayzak.org/sciencehouse/

Além do ambiente virtual de aprendizagem, interfaces multimídia como o Facebook, o Instagram, o Twitter, o Youtube, o Email, a Newslleter e o Linkdin fazem parte do leque de recursos utilizados no processo

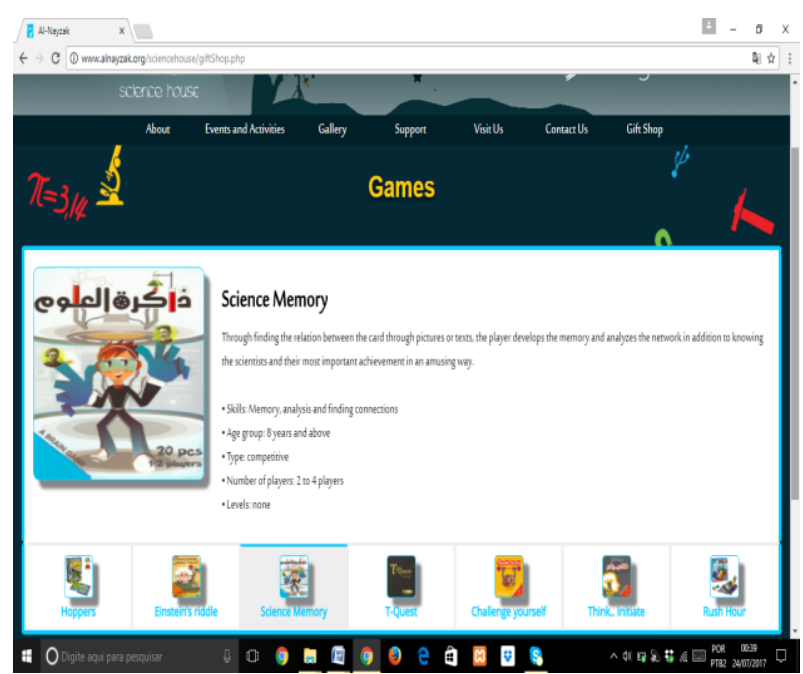

comunicativo entre a comunidade de utilizadores.

Figura 4. Website da Al Nayzak (Games)

Fonte: www.alnayzak.org/sciencehouse/giftShop.php

Seus projetos têm uma eficácia notável de forma qualitativa e quantitativa, uma vez que têm impacto em um grande número de classes sociais e segmentos sociais palestinos. Além disso, esses projetos permitem que cidadãos criativos e empreendedores apresentem seus talentos e habilidades científicas, possibilitando para alguns deles a chance de apresentarem suas propostas para o mercado local e internacional. Um dos quais, se destaca o jogo Interactive Space, voltado ao ensino da física e desenvolvido por programadores palestinos: 


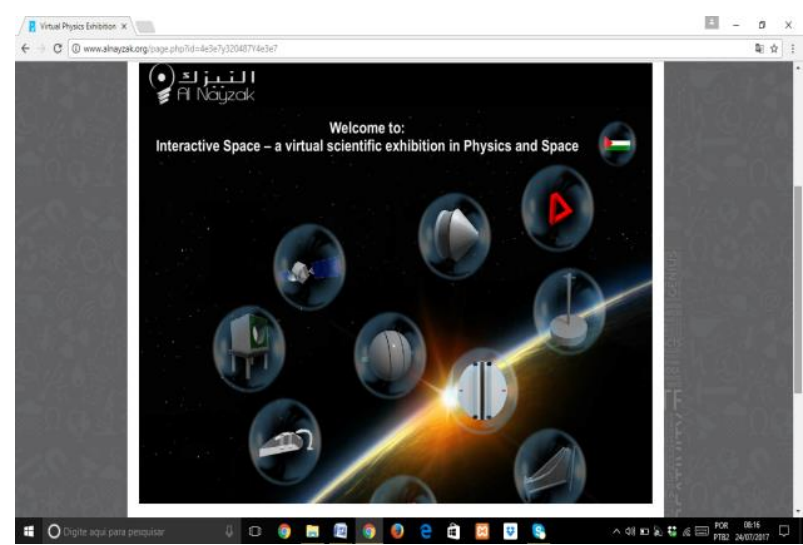

Figura 5. Game Interactive Space

Fonte: www.alnayzak.org/page.php?id=4e3e7y320487Y4e3e7

\section{Conclusão}

Faz-se notório que a ampliação da ocupação de territórios palestinos vem gradativamente limitar o desenvolvimento tecnológico em escolas e universidades palestinas, e a inserção de crianças e adolescentes numa sociedade em rede global, conectada e destituída de presencialidade corpórea. Nesse sentido, o cenário observado pelo professor Marcelo Teixeira na Palestina sobre a comunicação móvel nos espaços públicos e escolares, em 2014, sofreu declínio face às intervenções militares de Israel, o que seria diferente se houvesse em acordo de paz entre ambos Estados Nacionais. A grande diferença nesses últimos anos foi concessão de bolsas de estudo para universitários palestinos, principalmente nas áreas de engenharia da computação e ciências sociais, advindas de países da Europa e Canadá.

Por outro lado, os árabes-israelenses que vivem em Jerusalém, Tel Aviv, Haifa e em outros centros urbanos de Israel, gozam de excelentes escolas de ensino fundamental, médio, técnico e universitário, equiparados por um sistema de ensino sem distinções, inclusive, a cultura israelense considera o ensino superior como a chave para maior mobilidade e status socioeconômico na sociedade. Ademais, grande parte da população judaica considera à educação como um passaporte para um trabalho qualificado e um salário condizente numa economia de alta tecnologia altamente competitiva do país. Daí a explicação das ótimas universidades ali existentes, sempre entre as melhores do mundo.

À medida que a economia de Israel é em grande parte científica e tecnológica, o mercado de trabalho exige que pessoas que tenham conseguido alguma forma de ensino superior, particularmente relacionadas com ciência e engenharia, para ganhar vantagem competitiva na busca de emprego, tanto dentro quanto fora do país.

De forma positiva, em West Bank (Cidade de Qalqilya, Cisjordânia, Palestina https://vimeo.com/221264176), apesar de estar cercada por uma barreira israelita, vem crescendo em níveis educacionais, muito por causa dos programas educativos patrocinados pelo governo local e de fundos sociais doados por países do Oriente Médio, como o Catar. Aqui, temos no mês de Agosto atividades sociais para crianças e adolescentes que incluem o ensino do Inglês, da fotografia, produção de vídeos, etc. Por incrível que pareça, em se tratando de uma cidade de conflitos, há dez anos foi realizado um senso que evidenciou que $95 \%$ da população era alfabetizada. Existem duas faculdades na cidade: o Colégio Islâmico Ad Da'wa estabelecido em 1978 e um campus da AlQuds Open University estabelecido, em 1998, segundo o Instituto de Pesquisa Aplicada - Jerusalém, em 2013 (http://vprofile.arij.org/qalqiliya/pdfs/vprofile/Qalqiliya _vp_en.pdf). Ora, a educação é valorizada como forma de mudança social, especialmente por conta das oportunidades de bolsas de estudos ofertadas (como já mencionado), no ensino médio e superior.

São algumas realidades exemplificadas em meio a outras tantas que não têm espaço na mídia internacional, reduzida a transmissão de conflitos. $\mathrm{Na}$ prática, a sociedade global precisa se dedicar a resolver o problema das desapropriações de terra em territórios palestinos e do congelamento da ampliação dos assentamentos, além de proporcionar um cenário viável de incentivos (financeiros) que levem ambos países a se respeitarem mutuamente, como ocorre na relação secular das três religiões dominantes da Cidade de Jerusalém (cristianismo, judaísmo e islamismo).

Enfim, novos modos de vida são permeados por uma cultura global que potencializa novas formas de sociabilidade no mundo contemporâneo através de tecnologias digitais. Em outras palavras, trata-se de uma virtualização cultural da realidade humana, fruto da migração do espaço físico para o virtual (mediado pelas TICs), regido por códigos, signos e relações sociais próprias.

Avante, surgem formas instantâneas de comunicação, interação e possibilidade de rápido acesso às informações, no qual não somos meros emissores, mas produtores, reprodutores, colaboradores e distribuidores daquelas. As novas tecnologias também têm servido para "conectar" pessoas de diferentes culturas fora do espaço virtual, o que há pelo menos cinquenta anos era impensável, nas palavras de Teixeira (2013). Nessa gigantesca teia de relacionamentos, absorvemos, reciprocamente, crenças, costumes, valores, leis, hábitos, uns dos outros, heranças culturais eternizadas por uma dinâmica físico-virtual em permanente metamorfose. Não resta dúvida que a Al Nayzak é uma iniciativa inovadora que alinha a informática de ponta à educação. Entre as suas iniciativas, se destaca o curso presencial de robótica para adolescentes de 10 aos 13 anos de idade.

Nesse sentido, o panorama de tecnologia educacional em território palestino se diferencia no cenário de pesquisa vivenciado em 2014, quando não eram promovidas iniciativas semelhantes no espaço virtual.

$\mathrm{Na}$ contemporaneidade, criou-se um estigma globalizado que correlaciona o aparato tecnológico da escola, universidade, centro de ensino à qualidade da educação, sinônimo de mão de obra qualificada, mas nenhuma evidência científica lastreia o argumento de que tecnologias de informação e comunicação são decisivas na aprendizagem de jovens e adultos, como se constata em territórios da Autoridade Nacional 
Palestina. O que há, de fato, são limitações de recursos de um lado, e a vontade de estudar do outro, e quem ganha, no final, é o conhecimento.

\section{Referencias}

Aquino, C. D.; Teixeira, M. M. (2015). Comunicação midiática, hipertexto e interação. Raleigh: Lulu Publish.

Bauman, Z. (2001). Modernidade líquida. Rio de Janeiro: Jorge Zahar.

Baudrillard, J. (1981). Simulacres et simulation. Paris: Galilée.

Castells, M. (2009). Communication power. New York: Oxford University Press.

Cruz, C.; Ribeiro, U. (2004). Metodologia científica teoria e prática. Rio de Janeiro: Axcel Books.

Howe, J. (2009). O poder das multidões - por que a força da coletividade está remodelando o futuro dos negócios. Rio de Janeiro: Elsevier.

Gressler, L. (2004). Introdução à pesquisa - projetos $e$ relatórios. São Paulo: Loyola.

Malki, R. (2002). A questão da tecnologia no processo de paz. In Dupas, G. \& Vigevani, T. (Org) (2002). A construção da paz vista de uma perspectiva global, pp. 81-132. São Paulo: Editora Unesp.

Martins, G. (2008). Estudo de caso:Uma estratégia de pesquisa. São Paulo: Atlas.

Mustafa, M. M. \& Bisharat, K. (2008) Palestinian National Authority. In Ina Mullis, M. et al. Encyclopedia: a guide to mathematics and science education around the world. Boston: TIMSS \& PIRLS International Study Center.

Teixeira, M. M. (2014). A tecnologia educativa na Palestina: Da Omarieh School à Universidade Islâmica de Gaza. Revista Renote - Novas Tecnologias na Educação, vol. 12, n.2, pp. 1-10.

Teixeira, M. M. (2013). Da educação a distância às plataformas de e-learning: sistemas alternativos de educação mediada. Munique: Grin Verlag.

Teixeira, M. M. (2012). As faces da comunicação. Munique: Grin Verlag.

\section{Agradecimentos}

Grupo de Pesquisa Tecnologias Colaborativas em Saúde (TECNES) - Universidade Federal Rural de Pernambuco.

Coordenação de Aperfeiçoamento de Pessoal de Nível Superior (CAPES). 